\begin{tabular}{|c|c|c|}
\hline $\begin{array}{l}\text { PKS } \\
\text { PUBLIC } \\
\text { KNNOLEDGE } \\
\text { PROJECT }\end{array}$ & $\begin{array}{c}\text { REVISTA DE GEOGRAFIA } \\
\text { (RECIFE) } \\
\text { http://www.revista.ufpe.br/revistageografia }\end{array}$ & 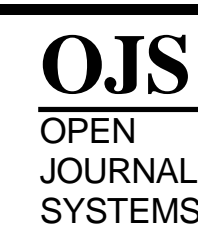 \\
\hline
\end{tabular}

\title{
ESPAÇO GEOGRÁFICO VIVIDO SOCIALMENTE: UMA APROXIMAÇÃO DA GEOGRAFIA CRÍTICA COM O HORIZONTE HUMANISTA
}

\author{
David Melo van den Brule
}

\begin{abstract}
${ }^{1}$ Especialista em Geopolítica e História pela Faculdades Integradas de Patos (FIP). Mestre em Geografia pela Universidade Federal da Paraíba (UFPB) e doutorando em Geografia pela Universidade Federal do Pernambuco (UFPE). Email: naturezageografia@gmail.com
\end{abstract}

Artigo recebido em 28/07/2016 e aceito em 23/08/2016

\begin{abstract}
RESUMO
O presente artigo examina como o conceito de espaço, fundamento da análise geográfica, consolidou-se ao longo do tempo. A opção de análise visa aqui privilegiar duas linhas de abordagens: a da Geografia Crítica, tendo como referência a obra de Milton Santos, e a escola de pensamento da Geografia Humanista, com as noções de espaço vivido. Este artigo, fruto de uma pesquisa bibliográfica, se propõe especificamente a trabalhar principalmente com as formulações de Milton Santos contidas nas obras Por uma Geografia Nova: Da Crítica da Geografia a uma Geografia Crítica, publicada em 1978 e A natureza do Espaço: Técnica e Tempo, Razão e Emoção, publicada em 1996. Considera-se importante também a contribuição da Geografia Humanista na abordagem do que seja o espaço, pois esta perspectiva validou questões subjetivas do ser humano, como o sentimento, a percepção, a identidade, a alteridade, o místico.
\end{abstract}

Palavras Chaves: Espaço Social; Milton Santos; valores.

\section{GEOGRAPHIC SPACE LIVED SOCIALLY: AN APPROACH OF CRITICAL GEOGRAPHY WITH HUMANIST HORIZON}

\begin{abstract}
This article will examine how the concept of space, the basis of geographical analysis, has consolidated over time. The option for the analysis aims to focus here two lines of approach: the Critical Geography, with reference to the work of Milton Santos, and the school of thought of Humanistic Geography, with the notions of been living space. This article, the result of a literature search, specifically proposes to work mainly with the formulations of Milton Santos contained in the works For a New Geography: The Critique of Geography to a Critical Geography, published in 1978 and The Nature of Space: Technique and Time, Reason and Emotion, published in 1996. important also considered the contribution of Humanistic Geography in approach about space, because this perspective validated subjective questions of the human, as the feeling, the perception, the identity, the alterity, the mystic.
\end{abstract}

Keywords: Social Space; Milton Santos; Values. 


\section{INTRODUÇÃO}

O espaço oferece algumas possibilidades e, ao mesmo tempo limitam outras, tornandose, muitas vezes repressivo. No estágio atual da humanidade, onde há uma hipervalorização do dinheiro e da informação, o estudo do espaço geográfico merece consideração, e sua reflexão revelará compreensões e transformações no modo de pensar e nele atuar, buscando uma visão mais ética, filosófica, humana e política.

Assim, o presente artigo examinará como o conceito de espaço, atualmente fundamental para a ciência geográfica, consolidou-se ao longo do tempo. Isso não significa afirmar a primazia de uma história linear, onde os conceitos subsequentes sejam "superiores" aos anteriores. De início vale ressaltar que, com o tempo, algumas contribuições foram bem desenvolvidas ampliando a compreensão e o tratamento dado para abordagem espacial. No entanto, saber como esse conceito foi sendo reelaborado e como sua compreensão poderá realinhar atitudes e valores é sem dúvida o foco deste trabalho. A opção de análise visa aqui privilegiar duas linhas de abordagens: a da Geografia Crítica, tendo como referência a obra de Milton Santos, e a escola de pensamento da Geografia Humanista, com as noções de espaço vivido.

Este artigo, fruto de uma pesquisa bibliográfica, se propõe a trabalhar principalmente com as formulações de Milton Santos contidas nas obras Por uma Geografia Nova: Da Crítica da Geografia a uma Geografia Crítica, publicada em 1978 e A natureza do Espaço: Técnica e Tempo, Razão e Emoção, publicada em 1996. Não significa que a proposta limitará apenas a esses dois volumes: todavia, quando se fizer necessário buscar-se-á referência em outras obras.

Considera-se importante a contribuição da Geografia Humanista na abordagem do que seja o espaço porque esta perspectiva buscou adentrar nas questões do ser humano, como o sentimento, a percepção, a identidade, a alteridade, o místico, etc. O presente texto utilizou-se principalmente das colaborações feitas por Antonio Christofoletti, Paulo Cesar da Costa Gomes e Roberto Lobato Corrêa.

Esta abordagem compõe-se fundamentalmente de três momentos. $\mathrm{O}$ primeiro deles ocupar-se-á de maneira sucinta com o conceito de espaço nos horizontes da ciência geográfica; o segundo discutirá, com mais ênfase, como Santos tratou o espaço nas obras supracitadas; e a terceira parte mostrará como a geografia humanista abordou o espaço 
(principalmente sob a perspectiva do vivido), e qual o valor dessa noção para os dias atuais tão conturbados.

\section{UMA BREVE ABORDAGEM DO ESPAÇO NAS ESCOLAS DE PENSAMENTO GEOGRÁFICO}

O espaço é uma noção cheia de subentendidos, de pressupostos e variações ao longo da história, portanto, polissêmico. Sua concepção foi alvo de análise desde a filosofia antiga transitando pela ciência, religião e senso comum. São diversas as abordagens a respeito do espaço: na Filosofia, na Arquitetura, na Física, na Sociologia, na Economia, na História e, principalmente, na extensa bibliografia geográfica.

Mesmo reconhecendo a interdisciplinaridade que há na abordagem do espaço, visa enfocá-lo no âmbito da ciência geográfica. Como afirmou o sociólogo Tonino Bettanini, "somente a geografia, em sua tentativa de reformulação, parece aproximar-se de uma reflexão epistemológica" do espaço (1982, p. 15).

Segundo Paulo Cesar da Costa Gomes, com o livro Geografia e Modernidade, publicado em 1996, a geografia teve, após sua institucionalização no século XIX, quatro grandes horizontes epistemológicos: A Geografia clássica, a Nova Geografia ou Geografia Quantitativa, a Geografia Crítica radical e o horizonte da Geografia Humanista.

$\mathrm{Na}$ Geografia Clássica ${ }^{1}$, corrente predominante até cerca de 1950, com influência do positivismo e do historicismo, valoriza-se as ciências da natureza, carregando a noção de espaço absoluto como elemento não mutável, portanto estático. CORRÊA (1995) ressalta F. Ratzel e R. Hartshorne como alguns dos representantes desta perspectiva. Nesta escola o espaço não se tornou um conceito chave, aparecendo como tal na geografia após a década de 1950.

A Nova Geografia - também conhecida como teorética e quantitativa, desenvolvida principalmente após a segunda guerra mundial —, o espaço foi trabalhado nas perspectivas de planície isotrópica, representação matricial e espaço relativo, destacando os avanços técnicos cartográficos com a pretensão de localizar e observar a organização e distribuição dos fenômenos no espaço. A Nova Geografia coloca a linguagem espacial relacionada com os

\footnotetext{
${ }^{1}$ Não se quer cometer injustiça com o que tem sido chamado de pensamento geográfico clássico. MENDONÇA; et al, (1982) escreveu que "El panorama del pensamiento geográfico clásico es algo más complejo de lo que en ocasiones se ha supuesto. Esa complejidad es consecuencia, entre otras cosas, del proceso de diversificación de perspectivas al que ya no hemos referido (...). (p.54). Simplesmente, neste pequeno texto, não se adentra na diversidade contida nesta escola de pensamento. 
números, com o planejamento, fazendo uso da estatística e da matemática. No período mencionado, ganha força o planejamento estatal e a construção de um espaço no modelo capitalista.

A Geografia Quantitativa também teve a pretensão de buscar o status científico do conhecimento através do positivismo lógico. Roberto Lobato Corrêa (1995) afirma que a visão de espaço nesta abordagem apresenta-se limitada, privilegiando a distância e relegando os agentes sociais a um segundo plano. Alguns autores citados por Corrêa são Schaefer (1953), Ullman (1954), Watson (1955) e Bunge (1966).

De acordo com Sposito, a “contribuição mais polêmica para a transformação do conceito de espaço foi trazida pela chamada geografia crítica ou radical, de base marxista, por nomes como Milton Santos, Horacio Capel, Henri Lefebvre, Richard Peet, entre outros" (2003, p.89). Iniciada na década de 1960, esta corrente propõe uma renovação para a Geografia. Esta escola critica a postura positivista e reconhece o método materialista, histórico e dialético como o mais apropriado para compreender as relações geográficas. Advoga para si a responsabilidade de compreender o conteúdo social que há no espaço. Temas anteriormente não tratados pelos geógrafos - como exemplo as desigualdades espaciais promovidas pelo modo de produção capitalista, os problemas da urbanização nos países subdesenvolvidos, etc. - passam a ser prioridade. O espaço agora é visto como campo de lutas, dividido em classes. A escola supramencionada ficou também conhecida como a geografia de denúncia, surgida sob a influência dos movimentos sociais, militantes na busca de justiça social. Segundo Camargo, foi "somente após os 20 primeiros anos de geografia crítica é que surgem novas teorias que buscam aplicar a base marxista ao espaço" (CAMARGO, 2005, p. 102). Os autores que trabalharam para esse acontecimento foram D. Harvey, H. Lefebvre, M. Castells, H. Capel, M. Santos, E. Soja, R. Peet, entre outros.

Na década de 1970, com a Geografia Humanista, a abordagem cultural ganha nova perspectivas de trabalho. O espaço é tratado como vivido, local das experiências e das representações, repleto de significado, esta corrente valoriza a vivência e busca compreender como as pessoas criam o significado de espaço, ganhando importância à intencionalidade, o indivíduo e a percepção do espaço.

A geografia humanista alicerçada na filosofia dos significados, com influência da fenomenologia, busca compreender como os homens atribuem valores e manifestam uma certa afetividade espacial. Alguns autores que contribuem para essa escola de pensamento, 
Yi-Fu Tuan, Edward Relph, Anne Buttimer, Paul Claval, Zeny Rosendahl, Roberto Lobato Corrêa, Werther Holzer, Lívia de Oliveira, entre outros.

Para se conhecer mais a respeito da evolução do conceito de espaço nas correntes de pensamento da geografia, importantes referências são o artigo Espaço, um conceito-chave da Geografia; de Roberto Lobato Corrêa (1995), contido no livro Geografia: conceitos e temas; o livro Geografia e Filosofia: contribuição para o ensino do pensamento geográfico, de Eliseu Savério Sposito (2003), volume que aborda, no terceiro capítulo, os conceitos de espaço (tempo), região e território; a obra de Luís Henrique Ramos de Camargo, A ruptura do meio ambiente: conhecendo as mudanças ambientais do planeta através de uma nova percepção da ciência: a geografia da complexidade, na qual, na segunda parte do capítulo dois, o autor discute o conceito de espaço geográfico nas escolas de pensamento da geografia.

Essa literatura não se restringe apenas aos três autores indicados, há na atualidade uma gama de artigos científicos, monografias, dissertações, teses e livros dedicados ao tema dos conceitos geográficos nas diversas escolas de pensamento. Considera-se que o pensamento geográfico refletido através das escolas - sejam elas, clássica, quantitativa, crítica radical ou humanista - não possui um estilo unidimensional ${ }^{2}$, uma via única de análise. Diga-se de passagem, se houvesse uma única via de pensamento, o empobrecimento da compreensão do espaço estaria instaurado. Esta pluralidade de acepções é a sua riqueza.

Esta pesquisa bibliográfica revela é como o espaço foi e é tratado de modo diverso a depender da escola de pensamento, da filiação filosófica, da abordagem metodológica, do plano epistemológico, conceitual e cultural de cada autor. Portanto, examinar como o uso dos conceitos guiará os projetos de vida no espaço constitui-se tarefa instigante.

\section{A CONTRIbUiÇÃo DE MILTON SANTOS PARA ANÁlise do ESPAÇO GEOGRÁFICO}

Os trabalhos desenvolvidos por Milton Santos desde a publicação de Por uma geografia nova (1978) até a obra A natureza do espaço (1994) têm sido marcados por um grande esforço para colocar a Geografia em um novo patamar dentro das ciências sociais e na busca de contribuir para uma epistemologia do espaço humano. Ruy Moreira destaca que nesses 18 anos, Milton lança

2 Diga-se que nesses horizontes geográficos existe uma dimensão paradigmática, ou seja, um conjunto de princípios, operações e seleção de ideias que os indivíduos conhecem, pensa e produz o saber.

\begin{tabular}{lll}
\hline Brule, 2017 & ISSN 0104-5490 & 10
\end{tabular} 
[...] toda uma progressão em livros, coletâneas, ensaios que avançam com o intuito de elaborar uma teoria social da Geografia, de Por uma Geografia Nova se desdobra no Metamorfoses do Espaço Habitado (fundamentos teóricos e metodológicos da geografia), de 1988, já antes passando pelo Pensando o Espaço do Homem, de 1982, e Espaço \& Método, de 1985, e desemboca no Técnica, Espaço, Tempo (globalização e meio técnico-científico e informacional), de 1994, que antecipa a natureza do espaço. (MOREIRA, Resenha, GEOgraphia - Ano. 1 - No 1 -1999)

Fez-se necessário esse "recorte" de sua obra, por motivos de tal trabalho apresentar as características de um artigo científico e por não comportar uma discussão minuciosa levando em consideração a totalidade da obra do autor, com cerca de mais de 300 artigos e mais 40 livros.

A escolha se fez por motivos de cunho epistemológico e temporal. Por uma geografia nova (1978) é considerado, pelo próprio autor, o primeiro volume consagrado ao tema geral que é o espaço humano. Neste livro Milton Santos propõe que a discussão na geografia, seja em torno do espaço, colocando-o como objeto de estudo da disciplina. Sua busca é de encontrar uma teoria e uma epistemologia do espaço que possibilite fornecer a explicação da realidade espacial e seus instrumentos de análise.

O segundo trabalho, a natureza do espaço: Técnica e tempo. Razão e emoção (1996), Santos deseja completar o que chamou em 1978 de projeto ambicioso. Neste livro trabalha para colocar a Geografia definitivamente no âmbito das ciências sociais, elaborando em um trabalho denso, com uma respeitável bibliografia de 570 títulos $^{3}$, uma verdadeira teoria e epistemologia do espaço, inserida no âmbito da teoria social crítica na busca da compreensão da totalidade e do período histórico vigente. Milton Santos colabora com o que no seu dizer é "um sistema de idéias que seja, ao mesmo tempo, um ponto de partida para a apresentação de um sistema descritivo e de um sistema interpretativo da geografia". (SANTOS, 1996, p. 18).

As duas obras co-existem, se complementam, apresentam, continuidade, maturidade e aprofundamento do que é o espaço para o geógrafo.

O valor da obra de Milton Santos é realçado por Paul Claval que segundo ele "O trabalho feito por Milton Santos para fundar a geografia sobre bases críticas e construtivistas foi mais largo e mais abrangente que o de seus contemporâneos (2004, p. 22), da mesma forma observa Horácio Capel (2002) "El impacto de su obra ha sido inmenso y se ha

\footnotetext{
${ }^{3}$ VASCONCELOS, Pedro de Almeida. A geografia nova de Milton Santos (1975-2001). In: BRANDÃO, Maria (org.) Milton Santos e o Brasil. São Paulo: Fundação Perseu Abramo, 2004, pp. 139-154. 
extendido a los científicos sociales de diversos países, siendo hoy reconocido como uno de los maestros de la geografía contemporânea".

\subsection{O VALOR SOCIAL DO ESPAÇO}

Considerado o filósofo do espaço, Milton Santos, trabalha para revelar alguns problemas que visam camuflar a realidade social contida neste. Sua preocupação central é a busca de uma nova orientação aos geógrafos a respeito do conceito de espaço. Este conceito foi longamente trabalhado na geografia como veículo de uma ideologia desenvolvimentista, preocupada em facilitar o domínio do capital. Desse modo afirma Milton Santos,

Desde sua criação como disciplina aspirante a um status científico e durante a primeira metade do século XX, reconhece-se essencialmente duas tendências da geografia. De um lado, certos autores lutavam para assegurar à geografia uma categoria científica [...] procuravam nela descobrir leis e princípios gerais [...] De outro lado, havia aqueles que, sob diferentes maneiras, procuravam fazer da geografia um corpo de conhecimentos imediatamente utilizável (...).

(SANTOS, 1978, p. 117)

Assim, desumanizando o espaço, a geografia se tornou nas suas palavras a "viúva do espaço".

Portanto, Milton Santos busca romper com a abordagem do espaço newtoniano e kantiano. Para Newton o espaço possui um valor absoluto, vazio, um receptáculo, independente de qualquer coisa, nas palavras de Milton Santos "foi Newton quem santificou a ideia de um espaço absoluto e imutável, do qual o espaço relativo seria uma medida" (SANTOS, 1978, p. 49).

Em Kant o espaço é visto como intuição pura, segundo o dicionário de filosofia de José Ferrater Mora, Kant vê o espaço como uma "forma da intuição sensível, ou seja, uma forma $a$ priori da sensibilidade [...]. Atributos do posicionamento kantiano ao espaço são a prioridade, independência da experiência, intuitividade e idealidade transcendental”. (MORA, 2001, p. 223-224)

Assim como Newton, Kant trabalha com a noção de espaço imutável, fixo, no qual os acontecimentos ocorriam sem interferência no andamento de sua dinâmica. A ciência geográfica influenciada por essa noção trabalha a ideia de espaço absoluto desde autores do século XIX, como Humboldt e Ritter, até a chamada geografia marxista da década de 1970. 
(CAMARGO, 2005). Portanto, a crítica central de Milton Santos é com a negligência de uma via social na abordagem espacial.

Após a teoria de Einstein, relatividade da simultaneidade, considerada por Boaventura de Sousa Santos $^{4}$ a primeira ruptura do paradigma da ciência moderna, revelando a necessidade de trabalhar a noção de espaço-tempo (relativo) e não mais absoluto.

Essa nova forma de pensar possibilita estudar como o tempo se torna espaço e de como o tempo passado e presente influência no funcionamento do espaço atual, tal possibilidade para esse estudo foi solucionada por Milton Santos através da análise da técnica, considerando que "toda técnica é história embutida, [...] é tempo congelado" (SANTOS, 1996, p. 48).

Portanto, o espaço não mais é apenas um mero reflexo da sociedade, mas também um fator social, produto histórico, uma instância da sociedade. De palco das relações sociais de produção, ele, o espaço, passa a possuir uma conotação ativa, "ele é simultaneamente produto e produtor; determinante e determinado" (SANTOS, 1978, p. 163) das relações sociais. "O espaço é, assim, uma dimensão ativa no devir das sociedades" (SANTOS, p. 186). Portanto, o espaço, urgi, replica, solicita, possibilita e responde as ações sociais, com uma certa autonomia. No próprio entender de Milton Santos, sob a influência Sartriana

Essa característica do prático-inerte de Sartre que se volta contra o seu criador é o fundamento mesmo da existência do espaço como estrutura social, capaz de agir e de reagir sobre as demais estruturas da sociedade e sobre esta como um todo. As determinações sociais não podem ignorar as condições espaciais concretas preexistentes.

(SANTOS, 1978, p. 182) (grifo nosso)

O espaço estudado deve ser aquele produzido pelo homem, sinônimo de estrutura social. Assim considerado, este aparece com força atuante nas transformações sociais. Para essa análise Milton Santos se utiliza da divisão territorial do trabalho que segundo ele "cria uma hierarquia entre lugares e, segundo a sua distribuição espacial, redefine a capacidade de agir de pessoas, firmas e instituições" (1996, p. 135).

O espaço do qual o autor analisa não é apenas o econômico, há um relevo importante para o dado político em suas anotações, principalmente no que se refere ao Estado, aos

\footnotetext{
${ }^{4}$ Segundo Boaventura de Sousa Santos, em seu livro Um discurso sobre as ciências, publicado em 1987, o paradigma dominante (fruto da racionalidade científica moderna) conheceu cinco condições teóricas para a sua crise: I - O princípio da relatividade da simultaneidade de A. Einstein; II - O princípio da incerteza de W. Heisenberg; III - O teorema da incompletude, impossibilidade de K. Gödel; IV - Teoria das estruturas dissipativas e o principio da ordem através de flutuações, de Ilya Prigogine; V - Princípio da falsificabilidade de K. Popper.

Brule, 2017

ISSN 0104-5490 13
} 
Bancos e à participação das grandes empresas, que modelam o espaço multiplicando seus interesses.

O que o autor busca conhecer é como a força do espaço atua na reprodução da sociedade, bem como o inverso.

Contudo, podem-se distinguir dois grandes grupos de entendimento do que seja o espaço, aqueles que o consideram como algo exterior e, aqueles que se ocupam do espaço como um ser ontológico, possuidor de características próprias ${ }^{5}$.

\subsection{O ESPAÇO E SUAS CATEGORIAS ANALÍTICAS}

O ponto de partida de Milton Santos para compreender o espaço é como ele se apresenta nos dias de hoje, como um produto histórico, fruto da acumulação desigual de tempos, cada vez mais tecnificado, ao que denominou meio-técnico-científico-informacional.

Milton Santos aponta que ao longo de sua obra trabalhou com pares de categorias para o entendimento do que é o espaço. Na primeira formulação o espaço foi visto como um conjunto de fixos (instrumentos de trabalho) e fluxos (o movimento, a circulação). (SANTOS, 1978, 1987, 1988). Na segunda aparece a Configuração territorial (são o conjunto dos sistemas naturais, herdados por uma determinada sociedade, e dos sistemas de engenharia, isto é, objetos técnicos e culturais historicamente estabelecidos) e as relações sociais (SANTOS, 1988, 2001). E no terceiro momento (desenvolvido no livro A natureza do espaço) ele assume o entendimento que a dialética espacial se dá através do par, sistemas de objetos e sistemas de ação, visto de maneira indissociável. (SANTOS, 1996).

Em 1978, no encontro da Associação de Geógrafos Brasileiros (AGB) em Fortaleza, Milton Santos, lança o livro Por uma geografia nova: Da Crítica da Geografia a Geografia Crítica; marcando o movimento de renovação da geografia brasileira.

Neste, Milton destaca as categorias fundamentais do espaço, que chamará de: totalidade, sistema (social), o tempo, a escala e formação social ${ }^{6}$.

\footnotetext{
${ }^{5}$ A esse respeito ver a discussão que Santos coloca da noção de espaço de alguns autores, dos quais ele destaca: Bergson, Hettner, Bertrand Russell, Cassirer, Hegel, Campanella, E. Kant, W. E. Moore, H. Lefebvre, G. Leibniz, F. Perroux, E. Durkheim, etc. In: SANTOS, Milton. 1978, pp. 156-161. Ver também o debate colocado por E. SOJA (1989), no terceiro capítulo de seu livro Geografias Pós-Modernas: A reafirmação do espaço na teoria social crítica. Neste ele trabalha principalmente com as noções de espaço por D. Harvey, M. Castells e H. Lefebvre. Além disso, o artigo de Armando Corrêa da Silva que coloca a questão do espaço como ser, publicado no livro Geografia: teoria e crítica, organizado por Ruy Moreira (1982).

${ }^{6}$ Formação sócio-espacial é uma categoria de análise elaborada por Milton Santos, publicada inicialmente em 1977, na revista Antipode, nº 1, vol. 9, jan/fev, e posteriormente no livro Sociedade e Espaço (1982). Neste trabalho, Milton Santos acrescenta o espaço no método marxista da Formação Econômica e Social (F.E.S). O Brule, 2017 ISSN 0104-5490 14
} 
Estudando o homem, a natureza transformada, as relações sociais, o tempo, as relações entre forma, função, processo, estrutura e a organização do espaço atual, Milton Santos propõe um novo debate, ampliando a compreensão espacial dos geógrafos, colocando o espaço como

[...] um conjunto de relações realizadas através de funções e de formas que se apresentam como testemunho de uma história escrita por processos do passado e do presente. Isto é, o espaço se define como um conjunto de formas representativas de relações sociais do passado e do presente e por uma estrutura representada por relações sociais que estão acontecendo diante dos nossos olhos e que se manifestam através de processos e funções. O espaço é, então, um verdadeiro campo de forças cuja aceleração é desigual. Daí porque a evolução espacial não se faz de forma idêntica em todos os lugares.

(SANTOS, 2004 [1978] p. 153) (grifo nosso)

O trecho, acima citado, revela as categorias analíticas das quais Milton Santos se ocupou em trabalhar, estrutura, processo, forma e função.

Segundo ele: estrutura (implica a inter-relação de todas as partes de um todo; o modo de organização), processo (ação contínua, mudança, o tempo), forma (aspecto visível de uma coisa) e função (atividade esperada da forma), SANTOS (1985). Nas categorias forma, estrutura e função Milton recebeu influência do filósofo Henri Lefebvre, categorias já trabalhadas no seu livro, A Revolução Urbana de 1970.

Tais categorias aparecem em outras obras de Milton Santos, a exemplo do último capítulo do livro Economia espacial: críticas e alternativas (1979). Pensando o espaço do homem (1982) e Espaço e método (1985).

Em a natureza do espaço (1996) o autor propõe como ponto de partida que o espaço seja entendido como um conjunto indissociável de sistemas de objetos e de sistemas ações. Nas suas palavras:

O espaço é formado por um conjunto indissociável, solidário e também contraditório, de sistemas de objetos e sistemas de ações, não considerados isoladamente, mas como um quadro único no qual a história se dá. No começo era natureza selvagem, formada por objetos naturais, que ao longo da história vão sendo substituídos por objetos fabricados, objetos técnicos, mecanizados e, depois, cibernéticos, fazendo com que a natureza artificial tenda a funcionar como uma máquina. [...] os sistemas de objetos condicionam a forma como se dão as ações e,

estudo de Marx recebe critica por ele pela ausência de uma leitura espacial, segundo Santos, não existe formação econômica a-espacial para os estudos da sociedade. Santos coloca modo de produção, formação social, espaço de maneira interdependente. "O modo de produção seria apenas uma possibilidade de realização e somente a formação econômica e social seria a possibilidade realizada” (SANTOS, 1982 p.13). 
de outro lado, o sistema de ações leva à criação de objetos novos ou se realiza sobre objetos preexistentes. É assim que o espaço encontra a sua dinâmica e se transforma.

(SANTOS, 2006, [1996] p.

O que Santos argumenta é que jamais os objetos podem ser analisados fora da existência dos conjuntos de práticas que neles se inserem. Levar em consideração a inseparabilidade de objetos e ações é perceber o valor cultural de cada sociedade, é dá importância à capacidade que os seres humanos têm de atribuir significado as coisas, é estudar também o percebido, transpondo a materialidade por que possui valores, carregado de significados socialmente estabelecidos.

Nas palavras do autor, "quando a sociedade age sobre o espaço, ela não o faz sobre os objetos como realidade física, mas como realidade social, formas-conteúdo". (SANTOS, 1996, p.109). Assim sua significação é sempre relativa de acordo com o tempo e espaço histórico.

No entanto, para trabalhar com esse sistema de objetos e sistema de ações proposto por Milton Santos, impõe-se compreender o significado que o autor dá as noções de sistema, de objeto e de ação, segundo ele "O sistema se define por um nódulo, uma periferia e a energia mediante a qual as características pioneiras elaboradas e localizadas no centro, conseguem projetar-se na periferia a qual será então modificada por elas”. (SANTOS,1978, p. 79).

Santos busca romper com a noção clássica de sistema, colocando-a como sinônimo de totalidade social. A concepção de sistema supõe hierarquia, inter-relações, interconectividade, totalidade, multidisciplinaridade, subsistemas, conjunto, movimento, processo, etc. Uma pequena mudança na parte pode mudar e causar uma enorme diferença no todo.

A respeito dos objetos Milton Santos coloca que

Para os geógrafos, os objetos são tudo o que existe na superfície da Terra, toda herança da história natural e todo resultado da ação humana que se objetivou. Os objetos são esse extenso, essa objetividade, isso que se cria fora do homem e se torna instrumento material de sua vida, em ambos os casos uma exterioridade.

(1996, p.72)

Considera que as ações podem resultar de necessidades, naturais ou criadas. Essas necessidades: materiais, imateriais, econômicas, sociais, culturais, morais, afetivas, são elas que conduzem os homens a agir. 
O estudo do espaço assim elaborado revela a existência de categorias analíticas internas e externas que ajudam na leitura do espaço proposto por Milton. As categorias analíticas internas são: a paisagem, a configuração territorial, a divisão territorial do trabalho, o espaço produzido ou produtivo, as rugosidades e as formas-conteúdo. E as categorias analíticas externas ao espaço são: a técnica, a ação, os objetos, a norma e os eventos, a universalidade e a particularidade, a totalidade e totalização, a temporalização e a temporalidade, a idealização e a objetivação, os símbolos e a ideologia. (SANTOS, 1996)

Complementando sua abordagem, Santos propõe "as noções fundadoras do ser do espaço, susceptíveis de ajudar a encontrar sua buscada ontologia: a técnica, o tempo e a intencionalidade, materializados nos objetos e nas ações”. (SANTOS 1996, p. 23).

Para Santos o fenômeno técnico deve ser visto filosoficamente, isto é, como um todo. Sobretudo a técnica deve ser vista como um dado político e só pode ser entendida através do seu uso. Assim, a técnica é também considerada por Santos como "um conjunto de meios instrumentais e sociais, com os quais os homens realizam sua vida, produz e, ao mesmo tempo, cria espaço" (SANTOS, 1996, p.29). Desse modo, Santos propõe que a geografia seja vista "como um estudo de caso para as filosofias da técnica" (SANTOS, 1996, p. 49).

De acordo com Santos, em cada lugar se superpõe a relação global-local expressa no binômio ordem universal e ordem local, a primeira busca impor uma racionalidade única, alicerçada na via consumista e mercadológica, e, portanto para a maioria da população perversa. Concomitantemente a ela amplia-se a realidade da ordem local, regida pela interação, pela cooperação, pela emoção e gentileza. Seguindo esse entendimento de Santos pode-se afirmar que o lugar é o verdadeiro espaço da revolução, da mudança, da esperança, ou seja, o espaço usado receberá outro tratamento, uma nova funcionalidade, que passará a ser prioritariamente social e solidária. A sua busca é de contribuir para um espaço mais humano, onde destaca que

Nosso problema teórico e prático é o de reconstruir o espaço para que não seja o veículo de desigualdades sociais e ao mesmo tempo, reconstruir a sociedade para que não crie ou preserve desigualdades sociais. Em outras palavras, trata-se de reestruturar a sociedade e dar uma outra função aos objetos geográficos concebidos com um fim capitalista, ao mesmo tempo em que os novos objetos espaciais já devem nascer com uma finalidade social. (SANTOS, 1982, p.81) 
Contudo, o valor do espaço é dado por sua utilização, a sua essência será revelada pela produção, funcionamento e principalmente naquilo que ele pode provocar, para isso se torna pertinente e importante perguntar por que, como e para que e para quem existe tal espaço?

O que se dá no mundo contemporâneo é a dialética global-local, essa relação está inserida na sua obra na tentativa de não sair dos postulados herdados da filosofia marxista da noção de totalidade 7 . Segundo ele, o caminho seria partir da "totalidade concreta como ela se apresenta neste período de globalização - uma totalidade empírica". (SANTOS, 1996, p. 115).

Atualmente é possível conhecer o acontecer da humanidade por mais longínquo pareça graças aos avanços tecnológicos, mas também é sabido que esse avanço não chegou a todos, a cada novo avanço as contradições se alastram, esse crescimento desigual favorece aqueles que mais contribuem para o sistema capitalista, onde os necessitados de recursos materiais, não têm vez. O avanço tecnológico é fruto de uma política de privilégios onde o processo de produção pode até ser coletivo, mas a sua apropriação é de acordo com o poder aquisitivo dos indivíduos.

Essa forma de proceder em relação ao espaço se derivou por que "sentindo-se externo ao meio natural, o homem moderno efetivou diferentes intervenções na natureza, baseado no conceito clássico do espaço absoluto, tridimensional, inerte e não participante". (CAMARGO, 2005, p. 76). O espaço ainda é então tratado como mercadoria, quantificável e vendável, o ser humano é divisível, relegado a um segundo plano, tem mais espaço sistema de objetos (recurso material) e sistemas de ações (ampliação das limitações) quem possui mais dinheiro e meios técnicos suficientes para agir nele.

No entanto uma das contribuições de Milton Santos foi a ruptura desse tratamento dado ao espaço. Ao analisar o contexto ao qual o espaço está inserido, sobressai o juízo de formaconteúdo e a inseparabilidade de sistema de objetos e sistemas de ações. Introduzindo o valor do espaço como significado não apenas individual, mas como construção e representação social, sem desconsiderar o individual e a intencionalidade. Dessa forma sua obra auxilia a

\footnotetext{
${ }^{7}$ Essa noção refere-se a ideia de que todas as coisas presentes no Universo formam uma unidade. "Cada coisa nada mais é que parte da unidade, do todo, mas a totalidade não é uma simples soma das partes", sendo assim o Todo é maior que a soma das partes. (Sob a influência de Sartre, Santos trabalha com as noções de totalidade (resultado) e totalização (processo), portanto a totalidade é sempre incompleta. Milton afirma que para compreender essa totalidade faz necessário o entendimento do funcionamento, de sua estrutura interna, das suas leis, da sua relativa autonomia. (SANTOS, 1978, 1996). De acordo com o princípio hermenêutico e dialético a parte é tão determinada pelo todo como o todo pelas suas partes. Porém Santos admite que essa verdade é parcial, por que para alcançar a verdade total, é necessário reconhecer o movimento conjunto do todo e das partes, através do processo de totalização. 
geografia a se inserir no debate da sociedade atual. Portanto a geografia de Milton é uma geografia da ação, do movimento espacial contemporâneo.

Entretanto, o que se segue é a tentativa de resgatar e valorizar algumas contribuições da Geografia Humanista como o princípio da alteridade e a noção do espaço vivido a partir da experiência humana dos lugares.

\section{A CONTRIbUiÇÃo dA GEOGRAFia huMANiSta PARA A NOÇÃo DE ESPAÇO VIVIDO}

Delimitar as origens e vias de análise da geografia humanista é uma tarefa árdua. A diversidade de abordagens é bastante ampla neste universo do saber. Gomes (1996) constatou que "é difícil ver neste movimento uma unidade ou uniformidade sobre o plano filosóficometodológico" (p.305). Não há de forma alguma um único caminho a seguir, por isso uma de suas características é o ecletismo. Pode-se considerar que a fenomenologia, o existencialismo, a psicologia, o marxismo, a hermenêutica, são algumas de suas influências. Assim, esta corrente busca fundamentos e "referências variadas, sem excluir nenhuma via, pois a exclusão é encarada como um risco de limitação e de empobrecimento". (GOMES, 1996 p.305).

Diversos autores fazem referência ao desenvolvimento inicial da geografia humanista. Segundo CAPEL (1982) a geografia humanista surge em reação aos postulados da ciência positiva, para MENDONÇA (1982) as bases da geografia humanista está, mesmo de forma marginal, na abordagem cultural de Carl Sauer, enquanto que CHRISTOFOLETTI (1985) fala que suas bases podem ser encontradas nos trabalhos de Yi-Fu Tuan, Anne Buttimer, Edward Relph e Mercer e Powell. A professora Lívia de Oliveira (2008) atuante deste movimento no Brasil, considera a participação de mais alguns autores como David Lowenthal, David Ley, J. Nicholas Entrikin, no entanto GOMES (1996) lembra a retomada dos estudos da obra L'homme et la Terre de Eric Dardel, em CLAVAL (1995) encontra-se uma retomada dos primórdios da geografia cultural com os europeus ao final do século XIX e início do século XX, com F. Ratzel, P. Vidal de La Blache, Otto Schuter, pontuando também os trabalhos desenvolvidos por Carl Sauer e a escola de Berkeley, entre outros.

Segundo HOLZER (2008) “a geografia Humanista foi o motor da renovação da Geografia Cultural Anglo-Saxônica nas décadas de 1970 e 1980”, assim fenomenologia e humanismo possuiriam relação na Geografia Cultural-Humanista. 
Contudo, coloca-se a geografia cultural como sub campo da geografia humanista, assim como a geografia das religiões como sub campo da geografia cultural. Na realidade são diversos os interesses da abordagem humanista na geografia, contando com a valorização dos aspectos da cultura, da história, da construção de identidade, da experiência de vida pessoal, da subjetividade, da intuição, da vinculação afetiva com o lugar, do simbólico, dos significados, das sensações e das representações, do místico e do sagrado, portanto do sentido da existência humana. Sendo assim um universo a ser explorado passa a ser a mente e o coração dos seres humanos.

$\mathrm{Na}$ realidade não se pretende fazer um resgate histórico aprimorado, mas apreciar as novas nuanças que ganha o conceito de espaço.

\subsection{O ESPAÇO VIVIDO, UM LUGAR-AMBIENTADO}

Nesta escola o conceito de espaço vivido ${ }^{8}$ refere-se como sinônimo de lugar ${ }^{9}$, o lugar do individuo, o ambiente onde ele encontra-se inserido por vias emocionais e afetivas. Assim sendo o espaço um lugar carregado de significados.

Em Antonio Christofoletti encontra-se que

[...] a noção de espaço envolve um complexo de idéias. A percepção visual, o tato, o movimento e o pensamento se combinam para dar-nos o nosso sentido característico de espaço, possibilitando a capacidade para reconhecer e estruturar a disposição dos objetos [...] a Geografia Humanística, a integração espacial faz-se mais pela dimensão afetiva que pela métrica. Estar junto, estar próximo, não significa a proximidade física, mas o relacionamento afetivo com outra pessoa ou com outro lugar. (1985, p. 230).

Enquanto Gomes (1996) coloca que o

[...] espaço, é considerado ao mesmo tempo como o resultado concreto de um processo histórico, e neste sentido ele possui uma dimensão real e física, ou como uma construção simbólica que associa sentidos e idéias. [...] o espaço sendo visto

\footnotetext{
${ }^{8}$ Segundo Holzer, W. (1992, apud CORRÊA, 1995 p. 31.) diz que a temática do espaço vivido está particularmente vinculada à geografia francesa e tem suas raízes sobretudo na tradição vidalina, mas também na psicologia genética de Piaget, na sociologia, de onde se retiraria os conceitos de espaço-regulação, espaçoapropriação e esaço-alienação e a psicanálise do espaço baseada em Bachelard e Rimbet, de onde sai a discussão sobre o corpo, o sexo e a morte.

${ }^{9}$ A respeito da evolução do conceito de lugar ver o artigo de HOLZER, W. O Lugar na Geografia Humanista. Território, Rio de Janeiro, n. 7, p. 67-78, 1999. 
sob diferentes ângulos: dos valores, da alienação, da distância existencial, do comportamento e do mundo vivido. (p.307)

\section{Para Milton Santos o lugar representa}

[...] um cotidiano entre as mais diversas pessoas, firmas e instituições - cooperação e conflito são a base da vida em comum [...] O lugar é o quadro de uma referência pragmática ao mundo, do qual lhe vêm solicitações e ordens precisas de ações condicionadas, mas é também o teatro insubstituível das paixões humanas, responsáveis, através da ação comunicativa, pelas mais diversas manifestações da espontaneidade e da criatividade.

(SANTOS, 1996, p.322) (grifo nosso)

O lugar assume a base para a existência humana, experiência dos acontecimentos do cotidiano, como o viver, o consumo, o trabalho, a religião, o lazer, etc. Entretanto o lugar assume diversas escalas como afirma Tuan "uma poltrona perto da lareira é um lugar, mas também é o estado-nação". (1985, p. 149).

Portanto, considera-se o espaço vivido o espaço da experiência de vida, priorizando o sentimento, as crenças, o sagrado e também o profano, o mágico e o imaginário, os valores e as significações materiais e afetivas. Assim o lugar representa a expressão da singularidade construída e reconstruída cotidianamente, fruto das relações espaciais inseridas no que Milton chamou de sistemas de objetos e sistemas de ações. Para tanto, o estudo do espaço nesse horizonte valoriza as pessoas, considerando os seus sentimentos e ideias. Atualmente no mundo globalizado essa dimensão tem sido negligenciada, sendo o dinheiro e a informação as tiranias que comandam as ações de hoje.

A questão é ampliar o foco sem, contudo, excluir o ponto de vista proposto por Santos, que de acordo com Armando Corrêa da Silva "combina economia política, geografia, fenomenologia, e análise sistêmica" (1982, p.80).

No entanto para o geógrafo compreender essa abordagem do espaço é necessário ir a campo, partir para a pesquisa, fazer entrevistas, valorizar as descrições de experiências vividas. Na realidade para essa via "o geógrafo deve ser capaz de reunir o maior número de elementos possíveis que tratam dos valores, das significações e das associações construídas por um grupo social” (GOMES, 1996, p.314). 
A geografia humanista, ao privilegiar o estudo da singularidade e da individualidade, deve levar em consideração a integração dos elementos sociais (econômico, político, ideológico, religioso, cultural, etc.) respeitando a complexidade existente no espaço.

O espaço é indivisível, integral, uno e múltiplo ao mesmo tempo; a política é cultural; a experiência vivida é socialmente estabelecida; a economia gera novas políticas, por conseguinte as novas políticas geram novas formas de fazer economia; não se sabe ao certo onde uma termina e a outra começa. A realidade é uma só, o conhecimento desta pressupõe sua divisão servindo ao tratamento analítico, teórico e conceitual. O que o geógrafo em pesquisa revelará são alguns focos de prioridade a ser trabalhado. Assim a guia de análise não acontece apenas por horizontes e sim por temáticas.

\subsection{UNINDO PERSPECTIVAS}

Um ponto de vista está integrado a um universo particular do saber, com uma linguagem que lhe é própria. A multiplicidade dessas perspectivas é que faz o mundo dos homens. Acabar com isso é dar fim à própria humanidade. Dessa forma, busca-se a nãoredução da realidade, o não-estabelecimento de pressupostos fixos, propondo trabalhar os aspectos dinâmicos da interconectividade, da totalidade sempre se refazendo.

A questão aqui é considerar a possibilidade de trabalhar com as contribuições de Milton Santos, que vê e analisa o espaço em seu movimento contínuo de renovação, de constituição, de transformação, de reprodução, acrescentando a esta à análise do espaço vivido, na tentativa de valorizar o espaço dos homens, tornando-o mais humano.

Para isto seguem-se as reflexões de Ângelo Serpa contidas no boletim paulista de geografia, com o título de o trabalho de campo em geografia: uma abordagem teóricometodológica:

[...] afinal, não deveria haver incompatibilidade, em termos de procedimento, entre a análise da individualidade dos fenômenos e o resgate de sua dimensão histórica, nem mesmo entre uma concepção de ciência interessada na história e na mediação homem natureza e uma outra voltada para a essência dos fenômenos. [...] Portanto, dialética e fenomenologia não se excluem no trabalho de campo em Geografia. Enquanto métodos podem funcionar como estratégias complementares [...] Finalmente, é necessário enfatizar as múltiplas possibilidades da dialética, como a arte do falar e do pensar filosóficos, em nada incompatíveis com uma abordagem fenomenológica ou mesmo com procedimentos indutivos (ou dedutivos) na operacionalização da pesquisa e do trabalho de campo em Geografia. Assumir as contradições na produção do espaço não elimina a possibilidade de buscar a essência dos fenômenos nos seus diferentes recortes.

(SERPA, 2006 pp. 20-22). 
Nesta tarefa se impõe uma análise que seja dialogada, integrada, transdisciplinar, unindo diversos pontos de vista que às vezes parecem desconexos e estranhos, esquecendo a postura que separa e, principalmente, afirmando a que une: unindo o homem à natureza, o espaço ao tempo, o sujeito ao objeto, nessa relação mútua.

Desse modo, o materialismo histórico e dialético e a fenomenologia poderão unir-se com o intuito de trabalhar o espaço produzido pelos homens numa visão mais esclarecedora. Não se quer agir sob a exclusividade de uma lógica, pois, operando dessa forma, o geógrafo corre o risco de deixar de fora importantes frações de estudo, já que a ênfase dada a um modelo de análise pode ser mais reveladora em determinado momento, já em outro, uma perspectiva diferente poderá ser mais compreensível.

Utilizar valores que o humanismo legou, como a alteridade (todo homem social interage e interdepende de outros indivíduos), a valorização do outro, da diversidade, da diferença, ou seja, o respeito mútuo, se apresenta como um caminho. Neste sentido, trabalhar com sentimento, com a afetividade, buscando compreender a subjetividade, é também colaborar para a produção de um espaço mais humano, mais propenso à construção de valores, que não sejam apenas o econômico, na busca por aquilo que ele poderá ter de melhor: homens e mulheres vivendo em paz, objetivando a justiça e o desenvolvimento da consciência.

Quando os homens, ao produzirem espaço, se colocarem no lugar do outro, com consideração e valorização do diálogo permanente, poderão não serem vítimas daquilo que Martin Luther King disse na segunda parte de sua frase: "ou aprendemos a viver como irmãos, ou vamos morrer juntos como idiotas".

Portanto, ao olhar o espaço, vê-se o mundo dos homens, não apenas o mero reflexo dos mesmos, mas a sua própria extensão.

\section{CONSIDERAÇÕES FINAIS}

$\mathrm{Na}$ verdade existe um espaço social, pessoal, relativo, mítico, geométrico, concreto, distante, próximo, vivido, dividido, total e, sobretudo da vida, da gente, dos homens e das mulheres. A geografia proposta aqui não trabalha com um espaço sem gente, ou seja, sem um determinado número de pessoas que têm em comum certas características, ou profissão, ou interesse pessoal. Neste sentido, todo o espaço é social, depende de interesses divergentes e 
de grupos diversos que reivindicam para si o seu uso. Cada ser tem direito a espaço. Este direito, entretanto, para alguns não é concedido. O espaço, assim como os seres humanos, é repleto de contradições, conflitos, solicita ampliação e é também fragmentado, relacionado e carregado de emoção.

A compreensão e o valor que os homens dão ao espaço servirão de guia na construção de objetos sociais, porque a maneira como o homem percebe seu mundo e da forma que lhe atribui algum valor, irá constantemente influenciar na sua ação e no seu movimento diário.

Considera-se que existe a possibilidade de conhecer a realidade através da intuição, da subjetividade, mas o que se quis foi tão somente levar em consideração, e não abraçar essa análise com dogmatismo. Deve-se buscar um equilíbrio, uma moderação deste subjetivismo para não cair no relativismo exagerado, propondo um olhar atento para em nenhum momento se apropriar de regras deterministas, imutáveis e verdades absolutas. Como revela, Boaventura de Sousa Santos "a prudência é a insegurança assumida e controlada" (1987, p. 91).

O que se colocou em discussão foi como a noção de espaço ganhou diversas abordagens ao longo do desenvolvimento da geografia. Relacionando principalmente as abordagens proferidas por Milton Santos e as noções do espaço vivido da Geografia Humanista.

Reconhecer a complexidade e a mutabilidade do conceito de espaço, considerado como uma estrutura da sociedade, formado indissociavelmente por um conjunto de sistemas de objetos e sistemas de ações, repleto de intencionalidade, racionalidade, emoção, experiência, sentimento, representações e, sobretudo de vida, ganhando força o lugar na construção de um espaço mais ético, humano e solidário, possibilita pensar em outra forma de produzi-lo.

\section{REFERÊNCIA BIBLIOGRÁFICA}

BETTANINI, Tonino. Espaço e ciências humanas. Tradução de Liliana Laganá Fernandes; revisão técnica de Moacyr Marques. Rio de Janeiro: Editora Paz e Terra, 1982. [1976] BRANDÃO, Maria (org.) Milton Santos e o Brasil. São Paulo: Fundação Perseu Abramo, 2004.

CAMARGO, Luís Henrique Ramos de. A ruptura do meio ambiente: conhecendo as mudanças ambientais do planeta através de uma nova percepção da ciência: a geografia da complexidade. Rio de Janeiro: Bertrand Brasil, 2005.

CAPEL, Horacio. Filosofía y ciência em La geografia contemporânea. $3^{\text {a }}$ Ed. Barcelona: Editora Barcanova, 1988. [1981] 
CAPEL, Horácio. Continuar y superar a Milton Santos. In: el ciudadano, la globalización y la geografía. homenaje a Milton Santos. Scripta Nova. Revista electrónica de geografía y ciencias sociales, Universidad de Barcelona, vol. vi, núm. 124, 30 de septiembre de 2002. Disponível em: <http://www.ub.es/geocrit/sn/sn-124.htm> Acesso em: 2 out. 2009.

CHRISTOFOLETTI, Antônio. Perspectivas da geografia. $2^{a}$ ed. São Paulo: Difel, 1985. CORRÊA, Roberto Lobato. Espaço: um conceito-chave da Geografia, In: CASTRO, Iná Elias de. CORRÊA, Roberto Lobato. GOMES, Paulo Cesar da costa. (organizadores). Geografia: conceitos e temas $7^{\mathrm{a}}$ ed. Rio de Janeiro: Bertrand Brasil, 2005, pp. 15-47. [1995]

CORREAA, Roberto Lobato e ROSENDAHL, Zeny. Geografia cultural: Introduzindo a temática, os textos e uma agenda. In: CORREAA, Roberto Lobato e ROSENDAHL, Zeny (organizadores). Introdução a geografia cultural. Rio de Janeiro: Bertrand Brasil, 2003, pp. 918.

CLAVAL, Paul. As abordagens da Geografia Cultural, In: CASTRO, Iná Elias de. CORRÊA, Roberto Lobato. GOMES, Paulo Cesar da costa. (organizadores). Explorações geográficas: percursos no fim do Século. $2^{\mathrm{a}}$ ed, Rio de Janeiro: Bertrand Brasil, 2006, pp. 89117 [1997]

ELIAS, Denise. Milton Santos: a construção da geografia cidadã. In: el ciudadano, la globalización y la geografía. homenaje a Milton Santos. Scripta Nova. Revista electrónica de geografía y ciencias sociales, Universidad de Barcelona, vol. vi, núm. 124, 30 de septiembre de 2002. Disponível em: <http://www.ub.es/geocrit/sn/sn-124.htm> Acesso em: 4 de outubro de 2009

HOLZER, W. O Conceito de Lugar na Geografia Cultural-humanista: uma contribuição para a geografia contemporânea. GEOgraphia, UFF/EGG,Niterói, RJ, v. 5, n. 10, p. 113-123, 2003 .

HOLZER, W. A Geografia Humanista no Brasil: apontamentos para uma epistemologia. In: I Colóquio Nacional de História do Pensamento Geográfico, 2008, Uberlândia - MG. Anais do I Colóquio Nacional de História do Pensamento Geográfico. Uberlândia - MG : Núcleo Geografia e Memória/UFU, 2008. p. 1-15. Disponível em: <http://www.ig.ufu.br/coloquio/textos/Werther\%20Holzer.pdf > . Acesso em 30 set. 2009.

GOMES, Paulo Cesar da Costa. Geografia e modernidade. Rio de Janeiro: Bertrand Brasil, 1996.

LENCIONI, Sandra. Região e Geografia. São Paulo: Edusp, 2003. [1999]

LIMA, Luiz Cruz, Eflorescência de uma Geografia Generosa. In: LIMA, Luiz Cruz (Org.). Conhecimento e Reconhecimento. Fortaleza: EDUECE, 2003, pp. 91-97.

MENDOZA, Josefina Gómez; JIMÉNEZ, Julio Muñoz; CANTERO, Nicolás Ortega. El pensamiento geográfico. $2^{\mathrm{a}}$ Ed. Madrid: Alianza Editorial, 1988. [1982]

MORA, José Ferrater. Dicionário de filosofia (tradução Roberto Leal Ferreira, Àlvaro Cabral) $4^{\mathrm{a}}$ Ed. São Paulo: Martins Fontes, 2001.

MOREIRA, Ruy. A natureza do espaço. Técnica e tempo, razão e emoção. (Resenha), In: GEOgraphia, Vol. 1, No 1, Universidade Federal Fluminense, 1999. Disponível em: <http://www.uff.br/geographia/ojs/index.php/geographia/article/view/13/11> Acesso em: 27 set. 2009, pp. 151-153.

OLIVEIRA, Lívia de. O humanismo na Geografia: a contribuição brasileira. In: I Colóquio Brasileiro de História do Pensamento Geográfico. , 2008, Uberlândia - MG. Disponível em: 
$<$ http://www.ig.ufu.br/coloquio/textos/HUMANISMO\%20NA\%20GEOGRAFIA\%20Contrib uicao\%20Brasileira.pdf $>$ Acesso em 30 set. 2009.

SANTOS, Boaventura de Sousa. Um discurso sobre as ciências. $13^{\mathrm{a}}$ Ed. São Paulo: Cortez, 2003. [1987]

SANTOS, Milton. Por uma Geografia Nova: Da Crítica da Geografia a uma Geografia Crítica. 6a ed. São Paulo: Edusp, 2004 [1978].

Espaço e sociedade. $2^{\text {a }}$ Ed. Rio de Janeiro: Vozes, 1982.

Espaço e método. São Paulo: Nobel, 1985.

O espaço do cidadão. $7^{a}$ Ed. São Paulo: Edusp, 2007 [1987]

Metamorfoses do Espaço Habitado: Fundamentos teóricos e metodológicos da geografia. 4a . Ed. São Paulo: HUCITEC, 1996. [1988]

. A natureza do espaço: técnica e tempo, razão e emoção. $4^{a}$ ed. São Paulo:

Edusp, 2004 [1996].

SERPA, Ângelo. O trabalho de campo em geografia: uma abordagem teóricometodológica. Boletim Paulista de Geografia, Seção São Paulo - Associação dos Geógrafos Brasileiros, número 84, p. 7-24, Jul, 2006.

SILVA, Armando Corrêa da Silva. O espaço como ser: uma auto-avaliação crítica, In: MOREIRA, Ruy (organizador) Geografia teoria e crítica: O saber posto em questão, Rio de Janeiro: Ed. Vozes, 1982, pp. 75-92.

SPOSITO, Eliseu Savério. Geografia e Filosofia: Contribuição para o ensino do pensamento geográfico. São Paulo: Unesp, 2004. 